\title{
A Nonparametric Approach to Estimating Growth Determinants in Sub-Saharan Africa
}

\author{
Michael Kwame Asiedu ${ }^{1 *} \quad$ Daniel Ofori ${ }^{2}$ \\ 1. School of Management Sciences \& Law, University of Energy \& Natural Resources, Sunyani \\ 2.Department of Entrepreneurship and Finance, Kumasi Technical University, Kumasi
}

\begin{abstract}
This paper provides a contribution to the growth empirics in sub-Saharan Africa with a focus on identifying the major determinants of long run economic growth among SSA countries. Being aware of the overwhelming dominance of parametric regression methodology in the extant literature and its associated numerous setbacks, we specifically employ the local linear kernel estimator which does not assume any functional form for the underlying growth model. At the end of the study, the findings suggest that there is a positive and nonlinear relationship between economic growth on one hand as well as investment in physical capital, population and democracy on the other hand. Again, while we find that human capital and inflation have no significant effect on economic growth over the study period, foreign aid was found to have negative effect on economic growth in SSA. The findings obtained in the paper have important implications for growth policy in SSA. Growth policies should thus consider population control, expanding and improving the quality of education and enrolment especially at the higher levels and strengthen democratic institutions. For research, the findings imply that researchers should be cautious in specifying the functional form of growth models when investigating the determinants of economic growth.
\end{abstract}

Keywords: Bandwidth, economic growth, local linear kernel regression, nonparametric, sub-Saharan Africa

DOI: $10.7176 / \mathrm{JESD} / 12-16-02$

Publication date:August $31^{\text {st }} 2021$

\section{Introduction}

Economic growth is one of the key indicators of economic performance of any given country and region. Thus, interest in factors that determine economic growth of countries and regions has attracted considerable amount of attention in both theoretical and empirical growth literature especially after the publication Robert Solow's paper in 1956. Using different conceptual and methodological frameworks, these studies have come out with several set of variables that determine economic growth. Notwithstanding, the search for factors that explain economic growth among countries still continues. A popular feature of studies in empirical growth literature is the dominance of parametric methods based on linear specifications of growth models. Parametric methods assume functional forms for the specified models which may or may not be correct. Thus, estimators used in these models provide efficient and consistent results under very strict assumptions and/or conditions, a situation that affects the robustness of the estimates. As a result, the findings are usually contradictory which eventually adversely affects the inferences and conclusion drawn. For instance, while Sala-i-Martin (2004), Mankiw et al (1994) and Barro (1991) found positive impact of human capital on economic growth others such as Krueger and Lindahl (2001) Pritchett (2001) and Topel (1999) found negative relationship between human capital and economic growth. In much the same way, trade openness has been found to accelerate growth by Sakyi et al (2014), Yanikkaya (2003) and Wacziarg (2001) but others like Vamvakidis (2002) as well as Rodriguez and Rodrik (1999) concluded that trade openness has significant negative growth effects.

This study thus contributes to the growing literature on determinants of economic growth by applying the nonparametric regression method (specifically the local linear kernel estimator) which does not impose any structure on the data or specify any functional relationship prior to estimation. Through this approach, the supposed factors that drive the growth process of sub-Saharan African countries would be identified. Besides, to the best of our knowledge, nonparametric methodology has not been utilised in growth literature specifically related to sub-Saharan Africa. In addition, we also consider large number of sub-Saharan African countries covering relatively longer period of time.

It is an indisputable fact that Sub-Saharan African countries lag behind their counterparts in North America, Western Europe as well as Japan in terms of aggregate standard of living and infrastructural development (Romer, 2006, Sala-i-Martin and Barro, 2009, among others). While some countries like South Korea, Turkey and Israel appear to be making transition to membership in the group of relatively wealthy nations others including many in sub-Saharan Africa have had difficulty in obtaining positive growth rates of real income per capita. For this reason, the main focus of many governments of sub-Saharan African countries since independence from colonialism has been to find alternative ways of speeding up the rate of growth of aggregate output which will consequently lead to a decline in the prevalence of poverty in their respective countries. This is clearly exemplified in the many reformed programmes and policies they have pursued over the years and 
continue to pursue. Additionally, they have strived to maintain a relatively stable macroeconomic environment to stimulate economic activities. These notwithstanding, sub-Saharan African countries continue to be marginalised in terms of economic growth. The big question that is begging to be answered then is which variables or factors drive the growth process of SSA countries?

The economic performance of Sub-Saharan African countries has not only been inconsistent but also very abysmal compared with other developing countries of the same category. Many SSA countries show great potentials prior to independence and the periods immediately after independence. However, the following two decades presented some obstacles to many sub-Saharan African countries which resulted in stagnation or decline in economic performance. Since 1990s a lot of SSA countries ${ }^{1}$ have exhibited a modest recovery. Yet levels of economic performance remain quite below the immediate post-independence era. In a whole, the $0.9 \%$ average per capita income growth falls short by $1.5 \%$ in relation to other developing regions, and just about $3 \%$ below that of East Asian Economies and the high performing African (Botswana and Mauritius).

In view of the enormous emphasis placed on economic growth and its resulting measure of aggregate economic welfare, it becomes imperative to understand those variables that determine and drive the growth process of SSA countries. Many of the earlier studies on the growth covariates in SSA have adopted parametric regression methodologies to test specific dimensions or magnitudes of several variables. The results of many of the existing panel data studies face estimation challenges. For instance, the problem of unit root, cross-country dependence, cross-country heterogeneity, among others are often more difficult to address. Besides, most of the estimators used in parametric regression analysis are efficient and provide consistent estimates under strict assumptions and/or conditions, a situation that can affect the results and hence the conclusions drawn.

In order to circumvent the setbacks of the parametric methods identified above, we estimate our specified growth model nonparametrically using the local linear kernel estimator (LLKE) proposed by Li and Racine (2004). There are some benefits that can be derived from applying this estimator. Firstly, this estimator naturally takes care of interactions and nonlinearities among all the regressors as it jointly models the relationship among all the regressors. Secondly, among the class of nonparametric estimators, the local linear estimator has been found to be among the best boundary-correction methods. Finally, as argued by Li and Racine (2004), the resulting nonparametric estimator can have a convergence rate that is arbitrary close to the parametric rate when the underlying relationship is almost linear.

This study makes significant contributions to the literature. First, to the best of our knowledge, this is the only study that considers the nonparametric methodology and for that matter LLKE to investigate the determinants of economic growth in sub-Saharan Africa. Second, this study considers panel data from a large number of sub-Saharan African countries covering relatively longer period of time which makes the results more general than the earlier studies. Finally, we include in this study a large number of regressors so that the key factors that affect long run economic growth in SSA can be determined.

Eventually, the findings of the study suggest that there is a positive and nonlinear relationship between economic growth on one hand as well as investment in physical capital, population and democracy on the other hand. We also find that human capital and inflation have no significant effect on economic growth in SSA at least over the period considered for the study. The relationship between trade openness and real GDP though is nonlinear, it is a bit difficult to describe as it becomes negative after some threshold level and turns back to positive after a certain threshold value. Finally, we find in the study that foreign aid has negative effect on economic growth in SSA over the study period.

The rest of the paper is organised as follows: Section 2 provides an empirical review of growth determinants. Section 3 presents the description of the data and estimation techniques adopted in the study. Section 4 discusses the empirical results while Section 5 provides the conclusion and policy implications of the study.

\section{Determinants of economic growth: An empirical survey}

Clearly, two major theories dominate growth literature which discuss the role of various factors that determine economic growth among countries and regions. These theories are the neoclassical growth theory and endogenous growth theory. The neoclassical growth theory was developed by Robert Solow (1956) and highlights investment in physical capital as the major source of economic growth. This theory views technological progress as exogenously determined. One key prediction of the neoclassical growth models has to do with convergence. Those models predict that if a group of countries have the same steady state, then all things being equal, the poor countries in the group would grow faster than the rich countries.

The second theory is the endogenous growth theory pioneered by Romer (1986) and Lucas (1988). This theory emphasises the importance of human capital (knowledge) as well as invention and innovation (technological progress) in growth process. According to this theory, research and development activities are the

\footnotetext{
${ }^{1}$ Ghana, Cote d'Ivoire, Tanzania, Mauritius, Equatorial Guinea, Gabon and Botswana
} 
key drivers of knowledge and technological progress. Further, knowledge and technology exhibit increasing returns which drive the process of economic growth. New growth theory predicts that there will be no convergence due to increasing returns to scale.

In addition to the neoclassical and endogenous growth theories, other theories have emerged which have offered useful insights into the contributions of non-economic factors such as institutions, legal and political systems, socio-cultural and geographical factors. These theories have been championed by Gallup et al. (1999), Kaufmann et al. (1999), Brunetti (1997), Knack and Keefer (1997), North (1990), Matthews (1986) and Granovetter (1985).

Following from these theoretical developments, a wide range of empirical studies have flourished. Empirical studies in growth literature have come in two forms. The first form of studies generally focuses on convergence and/or divergence. That is, whether differences in aggregate economies over time would converge at equilibrium (See Mathur, 2005; Polanec, 2004; Barro and Sala-i-Martin, 1992; Barro, 1991; DeLong, 1988; Baumol, 1986).

The second form of studies which of course is the focus of many recent growth literature has sought to investigate the variables underlying economic growth. These studies have identified varied factors that explain the observed differences in economic growth across countries and regions over time using diverse methodologies (For example, Lucas, 1988; Romer, 1990; Barro, 1991; Summers and Heston, 1991; Mankiw, Romer and Weil, 1992; Sachs and Warner, 1997; Barro and Sala-i-Martin, 2004; Lensink and Morrissey, 2006).

In both endogenous growth models and extensions of the neoclassical models, human capital has been identified as a very important variable that explains differences in growth across countries. Proxy by levels of school enrolments, literacy rate, teacher-pupil ratio, among others, human capital concerns the technical knowhow and skills acquired by the population through education and other forms of training. Barro (1991) examined the relationship between human capital (using gross primary and secondary school enrolment rates) and growth rate of per capita GDP) from 1960 to 1980 for a number of countries and concluded that both gross primary and secondary school enrolment rates have positive and significant effects on rates of economic growth. Using a larger and seemingly better dataset, Sala-i-Martin (2004) concluded that human capital (proxy by male education) has positive correlation with growth while female education was insignificant. Other studies by Kyriacou (1991), Mankiw, Romer and Weil (1994), Benhabib and Spiegel (1994) all concluded that human capital enhances economic growth. Notwithstanding, other authors like Levine and Renelt (1992), Krueger and Lindahl (2001) and Pritchett (2001) have found contrary results and therefore questioned human capital as a growth covariate.

Another variable that has received tremendous attention as a principal determinant of economic growth in literature is trade openness. Apart from the comparative advantage theory, international trade obviously enhances efficiency in domestic markets, transfer of technology and provides the opportunity for the importation of capital and intermediate goods required for economic growth. This situation has led many economists to conclude that openness to international trade accelerates economic growth and development (Edwards 1992, 1998; Sachs and Warner, 1997; Wacziarg, 2001; Yanikkaya, 2003). Nonetheless, several other authors have obtained contrary findings (e.g., Levine and Renelt, 1992; Rodriguez and Rodrik, 1999; Vamvakidis, 2002).

Investment in physical capital stock has also been identified in literature as an important variable that promotes growth. Certainly, both the neoclassical and endogenous growth theories emphasise the significant role of investment in economic growth. Many of the studies found in the growth literature argue and conclude that investment in physical capital stock is the most fundamental variable that determines economic growth (See Lichtenberg, 1992; Levine and Renelt, 1992; Mankiw et al., 1992; Easterly, 1997; Barro and Sala-i-Martin, 2004; Artelaris et al., 2007).

Elsewhere in growth literature, democracy has also been discovered to be a significant determinant of economic growth. A more democratic institution provides the avenue for attracting foreign direct investments, foreign aid and above all redistributes income and resources in favour of the poor and marginalised in the economy. Additionally, democracy makes it possible for individuals to own property and establish businesses without any stringent restrictions. Thus, some existing studies have argued that democracy has a positive and significant impact on economic performance (see Rigobon and Rodrik, 2005; Roll and Talbott, 2003; Rodrik, 2002; Sala-i-Martin, 2002). Notwithstanding, other studies have obtained statistically negative relationship between democracy and growth (see Sakyi, 2011; Baum and Lake, 2003; Kurzman et al., 2002; Helliwell, 1994).

One variable in literature that has been emphasized an important determinant of economic growth is foreign aid. Aid enhances savings and capital mobilization. Besides, aid raises the ability to import intermediate goods and provides the conduit technological transfer which enhances the marginal productivity of capital in a domestic economy. Thus, aid contributes substantially to economic growth and income (see Gyimah-Brempong et al, 2007; Morrissey et al, 2005; Hansen and Tarp, 20000). However, some other studies found negative effect of aid on growth (for instance, Brautigam and Knack, 2004; Jensen and Paldam, 2003).

Within the endogenous growth models, Research and Development (R\&D) has been highlighted as an important source of economic growth. Research and Development activities result in inventions and innovations 
which lead to technological progress. This brings about the introduction of new and superior products which spur productivity growth and consequently economic growth. Other studies have empirically confirmed this assertion (e.g. Lichtenberg, 1992; Ulku, 2004; Artelaris et al., 2007).

The prevailing macroeconomic conditions as well as the economic policy stance of the government have also been emphasised as important determinants of economic growth. Generally, a relatively more stable macroeconomic conditions reduce risks and uncertainties associated with investment and hence provide a conducive environment for growth. Conversely, a macroeconomic instability resulting from high inflation tend to harmfully affect economic growth. Also, good economic policies resulting in improved infrastructures, investment in human capital and efficient institutions can spur economic growth. Barro and Sala-i-Martin (1995), Easterly and Rebelo (1993), Fisher (1993), Barro (1991, 1998), Grier and Tullock (1989) and Kormendi and Meguire (1985) have all concluded that macroeconomic conditions and economic policies play a significant role in economic growth.

\section{Empirical Methodology}

\subsection{Data Sources and Definition of Variables}

This paper covers the period 1970 to 2012 and considers a panel data for 32 Sub-Saharan African countries ${ }^{1}$. These countries were considered on the basis of data availability for the variables used in the study. Data were drawn mainly from the World Bank's WDI and African Development Indicators Databases. Real gross domestic product, human capital, investment in physical capital, foreign aid, trade openness, democracy, inflation and population, are the major variables considered in the study.

Real GDP is the monetary value of goods and services produced within the borders of an economy during a given year. It is measured using 2000 constant prices. Human capital concerns the technical know-how as well as skills and training acquired by the population. It is proxy by education measured here by gross primary school enrolment. Gross domestic capital formation as a percentage of GDP (a measure of gross domestic investment) captures the share of capital stock in promoting long run economic growth. AID here includes both official development assistance and net official assistance measured as a percentage of GDP. Trade openness considers the extent to which the economies of SSA countries are opened to international trade. Measured as a sum of export and import as a ratio to GDP, trade openness captures the role of external trade in economic growth. Democracy captures the impact of the political regime on economic growth. It is proxy by Polity 2 which is a continuous variable that measures the democratic quality of political regimes using polity scores ranging from 10 (strongly autocratic) to +10 (strongly democratic). Inflation reflects the annual percentage change in the general price levels in the economy. Measured here by the consumer price index, inflation reflects the macroeconomic conditions in the economy. Population includes all residents in a country regardless of their citizenship and it is used to control for country size.

\subsection{Model Specification and Method of Estimation}

In this paper, we investigate the factors that determine the growth process of sub-Saharan African countries in the long run. Theoretically, the neoclassical and endogenous growth models predict that investments in physical and human capital as well as technological progress are capable of explaining bulk of the differences in economic growth across countries. Nonetheless, there is still more room to account for other explanatory variables that explain changes in productivity and output growth among economies.

We therefore follow theory and earlier researchers and specify a growth model based on aggregate production function. In this specification, we see economic growth as dependent on human capital (Sala-i-Martin, 2004; Mankiw et al, 1994; Barro, 1991; Romer, 1990), investment in physical capital (Artelaris et al., 2007; Barro and Sala-i-Martin, 2004; Levine and Renelt, 1992), foreign aid (Gyimah-Brempong et al, 2007; Morrissey et al, 2005; Hansen and Tarp, 20000). Several other studies also stress the significance of trade openness in economic performance (Yanikkaya, 2003; Sachs and Warner, 1997; Wacziarg, 2001). Other regressors in the model include democracy (Rigobon and Rodrik, 2005; Roll and Talbott, 2003; Sala-i-Martin, 2002; Kaufmann et al. 1999), macroeconomic conditions (Barro, 1998; Barro and Sala-i-Martin, 1995; Fisher, 1993) and population (Siddique and Iqbal, 2005; Harrison 1996).

The growth equation to be estimated in this paper therefore takes the following general form:

$\mathrm{Y}_{\text {it }}=f\left(\mathrm{HUMCAP}_{\mathrm{it}}, \mathrm{INV}_{\mathrm{it}}, \mathrm{AID}_{\mathrm{it}}, \mathrm{TOP}_{\mathrm{it}}, \mathrm{DEMO}_{\mathrm{it}}, \mathrm{INFL}_{\mathrm{it}}, \mathrm{POP}_{\mathrm{it}}\right)+\mu_{\mathrm{it}}$

Where $i=1,2,3, \ldots ., N$ is the cross-sectional dimension of countries, $t=1,2,3, \ldots ., T$ represents time, $\mathrm{Y}_{\mathrm{it}}$ is the real GDP, HUMCAP ${ }_{i t}$ is human capital, $\mathrm{INV}_{\text {it }}$ is rate of investment in physical cpaital, AID $_{\text {it }}$ denotes foreign aid, $\mathrm{TOP}_{\text {it }}$ is trade openness, $\mathrm{DEMO}_{\text {it }}$ indicates democracy, INFL $\mathrm{It}_{\mathrm{it}}$ measures inflation, $\mathrm{POP}_{\text {it }}$ represents population and $\mu_{\mathrm{it}}$ is the white noise.

\footnotetext{
${ }^{1}$ Benin, Botswana, Burkina Faso, Burundi, Cameroon, Central African Republic, Chad, Democratic Republic of Congo, Republic of Congo, Cote d'Ivoire, Gabon, Ghana, The Gambia, Guinea-Bissau, Kenya, Lesotho, Madagascar, Malawi, Mali, Mauritania, Niger, Nigeria, Rwanda, Senegal, Sierra Leone, South Africa, Sudan, Swaziland, Togo, Uganda, Zambia and Zimbabwe.
} 


\subsubsection{Nonparametric Regression Technique}

A peculiar feature that distinguishes this study from earlier studies on growth in SSA is that it employs the nonparametric regression method which is expected to yield more robust and efficient results. As indicated earlier on, one major argument often advanced in favour of nonparametric methods is the incorrect functional specification of parametric models which sometimes results in wrong inferences. Thus, in an attempt to circumvent this weakness of the parametric method, Hsiao, Li and Racine (2007) consistent model specification test is applied in estimating the growth equation specified in (1) by employing the local linear kernel estimator (LLKE). LLKE is preferred in many nonparametric analyses because it is known to be among the best boundarycorrection methods so far. According to Li and Racine $(2004,2007)$ as cited in Adu (2012), when the underlying relationship is somewhat linear, the resulting nonparametric estimator can have a convergence rate that is arbitrarily close to the parametric rate. In addition, parametric specifications fail to capture possible interaction and nonlinearities which local linear kernel estimator does.

The estimation of the growth model in equation (1) involves three main steps. The first step involves evaluating the usual parametric specification by applying a consistent model specification test for correct parametric specification. This test is used to test the null hypothesis that the parametric model is specified appropriately. The null hypothesis takes the following form:

$$
H_{0}: P\left[E\left(Y_{i t} \mid X_{i t}\right)=m\left(X_{i t}, \alpha\right)\right]=1
$$

where $m(\cdot)$ is a known function (the assumed parametric regression model) with $\alpha$ being $q \times 1$ vector of unknown parameters.

The above null hypothesis is tested against the following alternative hypothesis:

$$
H_{1}: P\left[E\left(Y_{i t} \mid X_{i t}\right)=m\left(X_{i t}, \alpha\right)\right]<1
$$

Both hypotheses are tested by employing a statistical test which is based on the outcome of correct specification.

$$
\text { This demands that the residuals satisfy } E\left[E\left(\varepsilon_{i t} \mid X_{i t}\right)^{2}\right]=0
$$

specification. $E\left(\varepsilon_{i t} \mid X_{i t}\right)$ is consistently estimated using nonparametric methods. By the law of iterated expectations, $E\left[\varepsilon_{i t} E\left(\varepsilon_{i t} \mid X_{i t}\right)\right]$, a density weighted version is employed for the purpose of testing provided by $J=E\left[\varepsilon_{i t} E\left(\varepsilon_{i t} \mid X_{i t}\right) f\left(X_{i t}\right)\right]$, where $\varepsilon_{i t}=Y_{i t}-m\left(X_{i t}, \alpha\right)$ and $f\left(X_{i t}\right)$ is a joint probability density function. The reason for employing density weighting is to avoid the presence of a random denominator. Indeed, $E\left[E\left[\left(\varepsilon_{i t} \mid X_{i t}\right)\right]^{2} f\left(X_{i t}\right)\right] \geq 0$ Hence, $J$ provides a suitable statistic for testing both hypotheses. Thus, the statistic is computed as follows:

$$
J_{(N \times T)}=\frac{1}{N} \sum_{i=1}^{n} \sum_{t=1}^{T} \hat{\varepsilon}_{i t} \hat{E}_{-i t}\left(\varepsilon_{i t} \mid X_{i t}\right) \hat{f}_{-i t}\left(X_{i t}\right)
$$

where $\hat{\varepsilon}_{i t}=Y_{i t}-m\left(X_{i t}, \hat{\alpha}\right)$ is the residual derived by applying the parametric null model, $\hat{\alpha}$ is $\sqrt{N}$ consistent estimator of $\alpha$ under the null hypothesis of correct specification and $\hat{E}_{-i t}\left(\varepsilon_{i t} \mid X_{i t}\right) \hat{f}_{-i t}\left(X_{i t}\right)$ is a leave-one-out kernel estimator of $E\left(Y_{i t} \mid X_{i t}\right) f\left(X_{i t}\right)$.

Suppose the null hypothesis of correct specification of the parametric model is not accepted, implying misspecification of the parametric model, the next step then will be to estimate equation (1) using nonparametric methods. Specifically, this is done using the cross-validated local linear nonparametric estimator.

In the second stage, the growth equation in (1) is modelled in nonparametric form. To do this, we rewrite the model as

$$
Y_{i t}=g\left(x_{i t}^{c}, x_{i t}^{d}\right)+\varepsilon_{i t}, \quad i=1,2, \ldots, N ; t=1,2,3, \ldots, T
$$
where $x_{i t}^{c} \in R^{q}$ is a set of continuous (a subset of $X_{i t}$ ) regressors of dimension $q$ and $x_{i t}^{d} \in S \times S \times \ldots S$ is a set of discrete (a subset of $X_{i t}$ ) regressors of dimension $r$. The unknown conditional expectation $g(\cdot)$ and its derivatives cannot be observed but can estimated by employing nonparametric methods. This defined as 
$g\left(x_{i t}^{c}, x_{i t}^{d}\right): \beta\left(x^{c} \operatorname{def} \nabla g\left(x^{c}, x^{d}\right) \equiv \partial g\left(x^{c}, x^{d}\right) / \partial x^{c}\right.$ where $\nabla g(\cdot)$ is a $q \times 1$ vector.

Define $\delta\left(x^{c}, x^{d}\right)=g\left(x^{c}, x^{d}\right), \beta\left(x^{c}\right)^{\prime} \cdot \delta\left(x^{c}, x^{d}\right)$ is a $(q+1) \times 1$ vector-valued function whose first component is $g\left(x^{c}, x^{d}\right)$ and whose remaining $q$ components are the first derivative of $g\left(x^{c}, x^{d}\right)$ with respect to $x^{c}$.

Taking a Taylor series expansion of $g\left(x^{c}, x^{d}\right)$ at $x_{j}^{c}$, we obtain

$g\left(x_{i t}^{c}, x_{i t}^{d}\right)=g\left(x_{j t}^{c}, x_{i t}^{d}\right)+\left(x_{i t}^{c}-x_{j t}^{c}\right) \beta\left(x_{j t}^{c}\right)+R_{i j t}$

where $R_{i j t}=g\left(x_{i t}^{c}, x_{i t}^{d}\right)-g\left(x_{j t}^{c}, x_{i t}^{d}\right)-\left(x_{i t}^{c}-x_{j t}^{c}\right)^{\prime} \beta\left(x_{j t}^{c}\right)$

detailed

Thus, we rewrite equation (5) in the following form:

$$
\begin{aligned}
& Y_{i t}=g\left(x_{j t}^{c}, x_{i t}^{d}\right)+\left(x_{i t}^{c}-x_{j t}^{c}\right)^{\prime} \nabla g\left(x_{j t}^{c}, x_{i t}^{d}\right)+R_{i j t}+\varepsilon_{i t} \\
& =\left(1,\left(x_{i t}^{c}-x_{j t}^{c}\right)^{\prime}\right) \delta g\left(x_{j t}^{c}, x_{i t}^{d}\right)+R_{i j t}+\varepsilon_{i t}
\end{aligned}
$$

Equation (6) above is therefore estimated using the local linear kernel estimator ${ }^{1}$.

Applying this estimator requires optimal bandwidth selection. To do this, least-square cross-validation is used to choose the optimal bandwidth. Estimating the optimal bandwidth is analogous to the minimization of the error sum of squares in parametric regression analysis. But a leave-one-out method is used in the cross-validation function to avoid over fitting. A leave-one-out local linear kernel estimator of $\delta\left(x_{i t}^{c}, x_{i t}^{d}\right)$ is derived through a kernel weighted regression of $Y_{i t}$ on $\left(1,\left(x_{i t}^{c}-x_{j t}^{c}\right)^{\prime}\right)$ and $x_{i t}^{d}$.

This estimator is given as

$$
g_{-i}\left(x_{i t}^{c}, x_{i t}^{d}\right)=e_{1}^{\prime} \hat{\delta}_{-i}\left(x_{i t}^{c}, x_{i t}^{d}\right)
$$

where $e_{1}$ is a $(q+1) \times 1$ vector, whose first element is 1 and the rest being zero. Optimal bandwidth $(h, \lambda)$ is then chosen to minimise the least-squares cross-validation function given as

$$
C V(h, \lambda)=\sum_{i=1}^{N} \sum_{t=1}^{T}\left[Y_{i t}-\hat{g}_{-i}\left(x_{i t}^{c}, x_{i t}^{d}\right)\right]^{2}
$$

where $\hat{g}_{-i}\left(x_{i t}^{c}, x_{i t}^{d}\right)$ is defined in equation (7). The resultant bandwidth vector is represented by $(h, \lambda)$.

After deriving the correct bandwidth vector, $\delta\left(x_{i t}^{c}, x_{i t}^{d}\right)$ is estimated by

$$
\begin{aligned}
& \hat{\delta}\left(x_{i t}^{c}, x_{i t}^{d}\right)=\left(\begin{array}{c}
\hat{g}\left(x_{i t}^{c}, x_{i t}^{d}\right) \\
\hat{\beta}\left(x_{j t}^{c}\right.
\end{array}\right) \\
& {\left[\sum_{i=1}^{N} W_{\hat{h} i x}\left(\begin{array}{c}
1 \\
x_{i}^{c}-x_{j}^{c}\left(x_{i}^{c}-x_{j}^{c}\right)\left(x_{i}^{c}-x_{j}^{c}\right)^{\prime}
\end{array}\right) L_{\lambda i j}\left(x_{i}^{d}, x_{j}^{d}, \lambda\right)\right]^{-1} \times } \\
& \sum_{j=1} W_{\hat{h} i x}\left(\begin{array}{c}
1 \\
x_{i}^{c}-x_{j}^{c}
\end{array}\right) L_{\lambda i j}\left(x_{i}^{d}, x_{j}^{d}, \lambda\right) Y_{i t}
\end{aligned}
$$

where $W_{\hat{h} i x}$ is a product kernel for continuous data and $L_{\lambda i j}$ is a product kernel for discrete data.

The last step involves plotting the partial regression and partial gradient or partial response surfaces that measure how the log of real GDP and its response surface change in response to changes in one of the explanatory variables, holding all other variables constant at their modes/medians.

\section{Discussion of Empirical Results}

In this section, the empirical results arising from the data analysis are presented and discussed thoroughly. The

\footnotetext{
${ }^{1}$ See Li and Racine $(2004 ; 2007)$ for a thorough description of the local lineal kernel estimator.
} 
analysis begins with the consistent model specification test whose results are presented in Table 1 below. The consistent model specification test tests the null hypothesis of correct specification of the parametric model. The results of the test clearly indicate that the null hypothesis of correct specification is rejected at $0.1 \%$ level of significance.

Table 1: Consistent Model Specification Test

\begin{tabular}{|c|}
\hline Consistent Model Specification Test \\
\hline $\begin{array}{l}\text { Parametric null model: } \operatorname{lm}(\text { formula }=\log (R G D P) \sim \log (I N V)+\log (P O P)+\log (H U M C A P)+T O P+I N F L+ \\
D E M O+\log (A I D), x=\text { TRUE, } y=\text { TRUE }) \\
\text { Test Statistic 'Jn': } 16.29412 \quad[2.22 \mathrm{e}-16]]^{* *}\end{array}$ \\
\hline $\begin{array}{l}\text { Signifiant codes: } 0 \text { '***' } 0.001 \text { '**' } 0.01 \text { '*' } 0.05 \text { '.' } 0.1 \text { ' ' } 1 . \text { Number of regressors: } 7 . \text { IID Bootstrap (399 } \\
\text { replications). Null of correct specification is rejected at the } 0.1 \% \text { level. Value in [ ] indicates p-value. }\end{array}$ \\
\hline
\end{tabular}

Table 2: Estimated Bandwidth and Nonparametric Regression

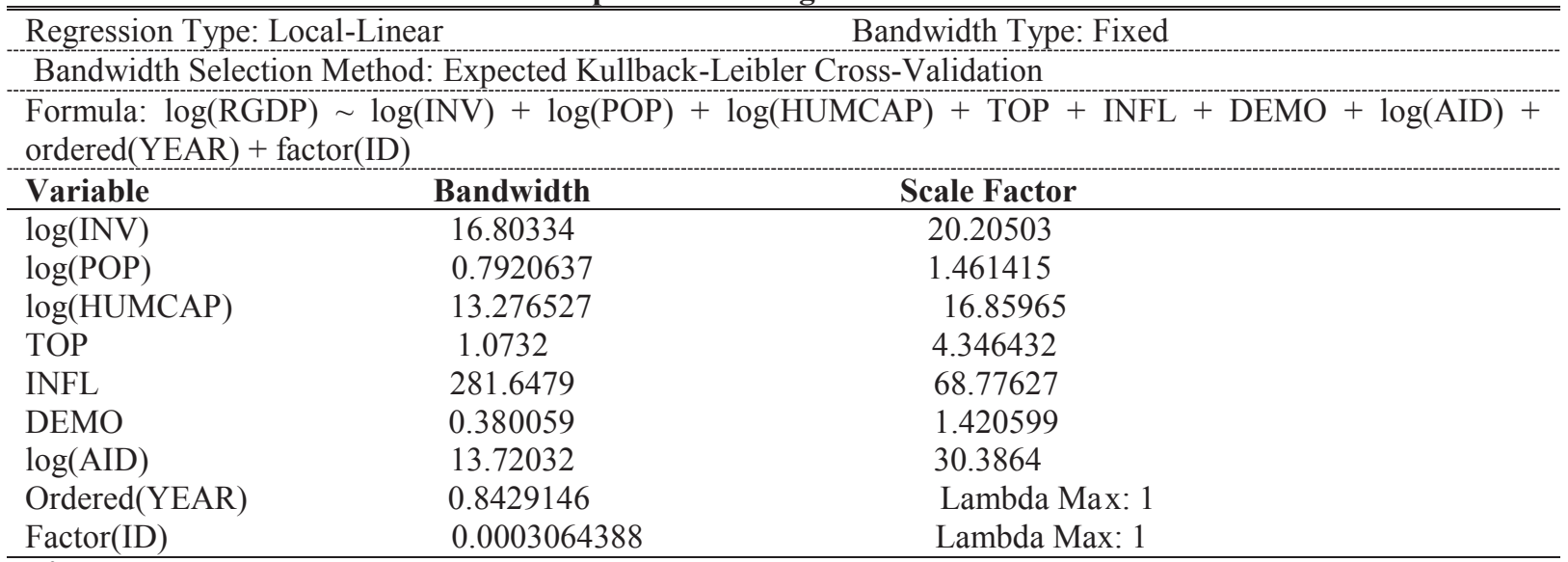

$R^{2}=0.9895478 \quad$ Residual Standard Error: 0.02874646

Objective Function Value: -4.355896 (achieved on multistart 5). Number of Continuous Explanatory Variables:

7. Continuous Kernel Type: Second-Order Gaussian. Number of observations: 1333. Number of ordered categorical variables: 1. Number of unordered categorical variables: 1. Unordered Categorical Kernel Type: Li and Racine. Ordered Categorical Kernel Type: Li and Racine. Estimation time: 32,254 seconds

The relative values (or sizes) of the bandwidth estimates show whether there is linear or nonlinear relationship between real GDP and the explanatory variables. Relatively larger bandwidth estimates for a regressor(s) suggest a linear relationship between real GDP and those regressors. Thus, as the relationship becomes linear the resulting nonparametric estimator converges to the parametric estimator on the coefficient on that variable. Conversely, relatively smaller bandwidth estimates is an indication of nonlinear relationship between real GDP and the regressors. The results from the table clearly indicate that with the exception of log of population $(\log (\mathrm{POP}))$, trade openness, democracy and the two categorical variables (the time index and country index) all the other variables have relatively large bandwidth estimates. As can be seen from the table, $\log (\mathrm{POP})$, TOP and DEMO have bandwidth estimates of approximately $0.792,1.073$ and 0.380 respectively which are close to zero. This means that the correlation among real GDP and trade openness, population, trade openness and democracy is nonlinear. The rest of the explanatory variables namely investment (INV), human capital (HUMCAP), inflation (INFL) and foreign aid (AID) have somewhat linear relationships with real GDP by virtue of the large sizes of their bandwidth estimates. The underlying relationships (linearity and nonlinearity) between real GDP and the various explanatory variables become more apparent when we consider the plots of partial regression and partial gradients as shown in Figures 1 and 2.

Following from the estimated bandwidths of the explanatory variables, we estimate the local linear kernel regression whose results are also reported alongside the bandwidth estimates in Table 2. As can be seen from the table, the nonparametric regression model provides a good fit of the data. This is evidenced in the relatively large $R$-squared value of 0.9895478 and a low residual standard error of 0.02874646 . The implication is that the selected explanatory variables namely, investment, population, human capital, trade openness, inflation, democracy and foreign aid account for approximately $98.95 \%$ of the observed variations in real GDP in SSA over the period under consideration.

In order to have a clearer understanding of the nature of the relationship between real GDP and the explanatory variables, we consider the partial gradients and partial regression plots. These are graphs that 
measure how the dependent variable (log of real GDP) and its response surface change if there is a change in any of the explanatory variables, when remaining variables are held constant at their respective modes/medians. They also provide estimates of the LLKE for the growth equation used in the study. All the figures plotted contain $95 \%$ variability bands. While Figure 1 shows the plots of the partial regression Figure 2 shows the plots of partial gradients.

The plot in Figure 1 shows that the relationship between real GDP and investment in physical capital is positive and linear. This means that as investment in physical capital increases real GDP also increases in SSA. As can be seen from Figure 2, the partial response surface of real GDP with respect to investment is constant confirming that the relationship is not only positive but also linear. This result is consistent with the expectation of neoclassical growth theory as well as many studies in the empirical literature (See Lichtenberg, 1992; Levine and Renelt, 1992; Mankiw et al., 1992; Easterly, 1997; Barro and Sala-i-Martin, 2004; Artelaris et al., 2007). Thus, investment contributes significantly to economic growth as it adds to the capital stock of a country and also replaces the reduction in the value of capital goods (i.e. depreciation). This increases the marginal productivity of capital culminating in growth.

The partial regression plots in Figure 1 suggest a positive relationship between real GDP and population. The plots in Figure 2 show that the relationship among population and real GDP is nonlinear with a response rate of between 1 and 1.05. As the plot shows, real GDP initially increases with increasing population but falls with increasing population beyond some level. This means that beyond a certain level, population could have negative effect on economic growth. A rise in population not only increases the market size and raises aggregate demand but also adds to the total labour force which go to enhance productivity and output growth. However, beyond certain level population could have negative effect on economic growth as increasing population is associated with unemployment, increased congestion, urban slums and poor sanitation especially in developing regions like SSA.

As can be seen from Figures 1 and 2, the relationship among economic growth and human capital is not only linear but also constant. This result clearly suggests that economic growth in SSA does not vary with human capital (measured in this study by gross primary school enrolment). This could probably mean that primary or basic education is not enough to provide the needed skills and trainings to improve the efficiency and marginal productivity of the population to contribute significantly to growth.

The relationship between real GDP and trade openness is a little bit difficult to describe. From the respective partial regression plots and partial gradient in Figures 1 and 2, it appears that the relationship becomes negative after some threshold level and turns back to positive after a certain threshold value. Notwithstanding, it is clear that the relationship is nonlinear. The implication of this is that the nature of the relationship (whether positive or negative) between trade and real GDP depends on the extent to which the economy is opened to international trade.

From the partial plots in Figures 1 and 2, the relationship between economic growth and inflation does not appear to be consistent. For most levels of inflation the relationship is constant.

Figure 1: Partial regression plots
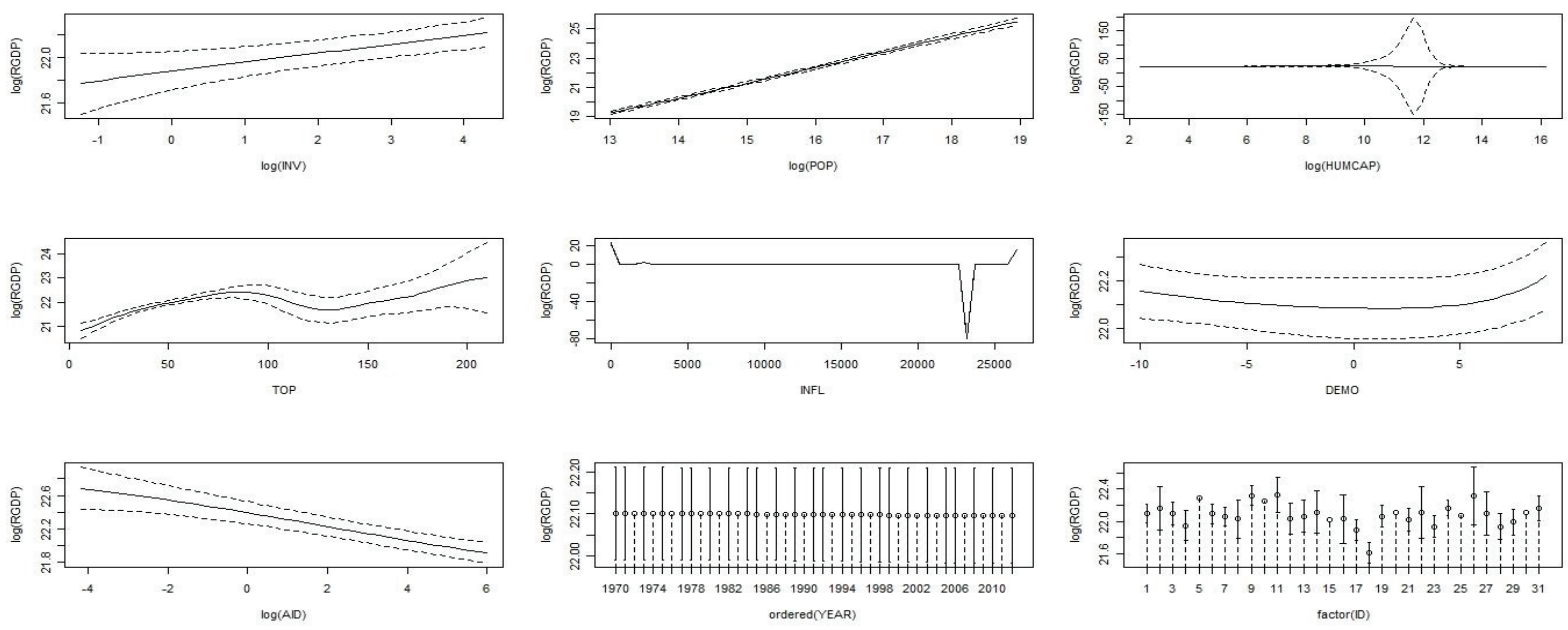

factor(1D) 
Figure 2: Plots of partial gradients
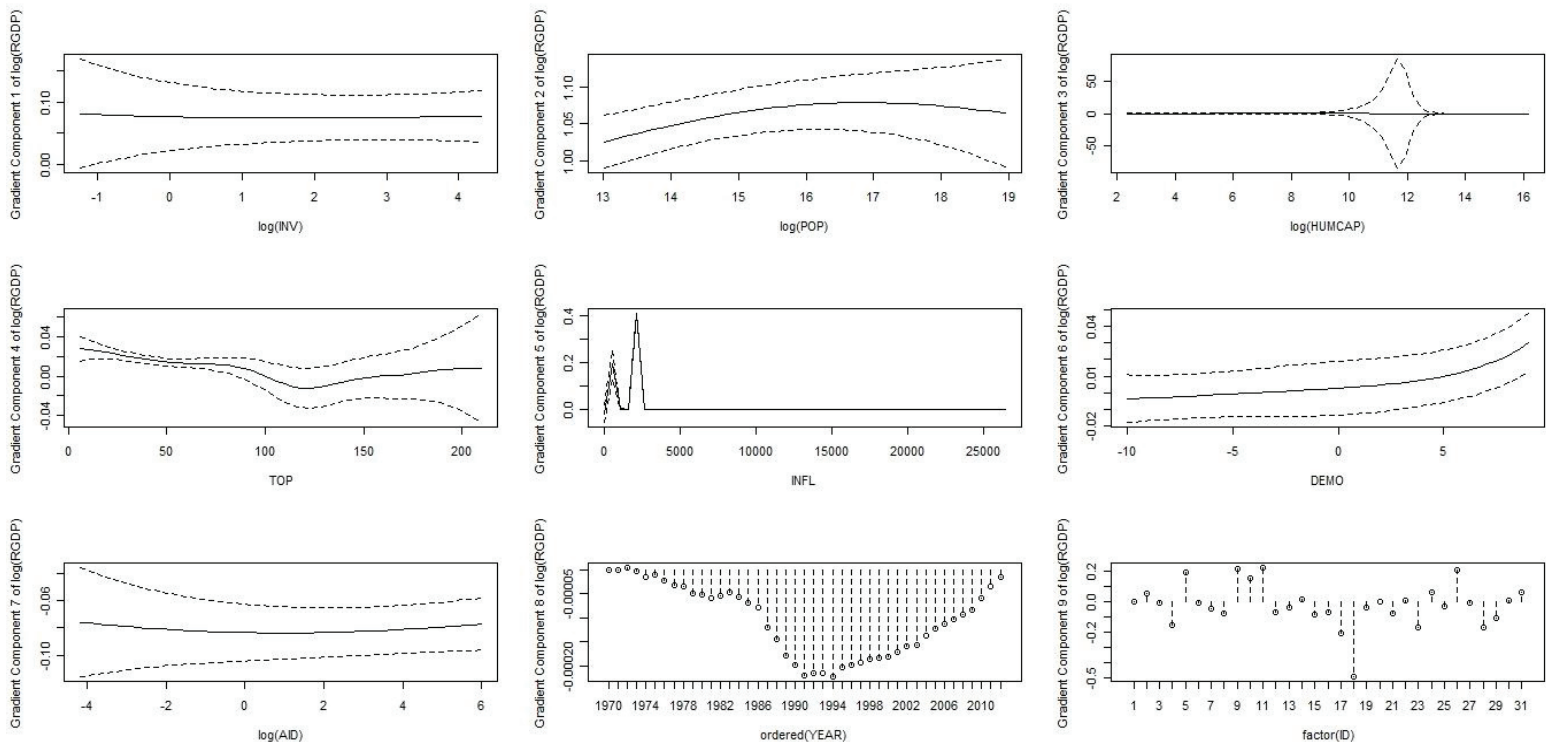

However, beyond certain threshold value real GDP falls and rises after a certain threshold level. This means that inflation did not significantly have any relationship with economic growth at least over most of the period under consideration. Thus, inflation had no significant effect on economic growth over the study period.

Further, the relationship between economic growth and democracy is not only positive but also nonlinear as shown in Figures 1 and 2. Clearly, the partial regression plot and partial response surface indicate that increased levels of democracy are associated with rising levels of economic growth. This result is consistent with theoretical expectations and many empirical studies that have found positive relationship between democracy and economic growth (see Jalles, 2010; Rigobon and Rodrik, 2005; Roll and Talbott, 2003; Rodrik, 2002; Sala-iMartin, 2002). Indeed, over the last two and a half decades, sub-Saharan African countries have witnessed a remarkable improvement in democratic governance which has provided a conducive environment for economic activities to thrive on and this is expected to improve economic performance.

Measured as official development assistance as a percentage of GDP, the log of foreign aid (log(AID)) exhibits a negative and linear relationship with real GDP. As the plot of partial regression in Figure 1 shows economic growth reduces with increasing aid inflows. The partial response surface in Figure 2 also shows that the relationship is almost linear implying that with time, increasing aid inflows will have no significant effect on economic growth in SSA. This result appear to be consistent with earlier studies such as Ndambiri et al (2012), Djakov et al (2006), Heckelman and Knack (2005), Easterly (2003), Collier and Hoeffler (2007).

\section{Conclusion and Policy Implications}

This study provides a contribution to the growth empirics in sub-Saharan Africa. It was conducted principally to identify those variables that contribute to long run economic growth among SSA countries. Mention must be made that large body of studies on the determinants of economic growth are found in the extant literature. However, these studies often adopt parametric regression methodology which assumes functional form for the specified model, a situation that has resulted in inefficient and inconsistent estimates leading to wrong inferences and conclusions due to functional misspecification. The search for an alternative methodology that circumvents the setbacks of the parametric analysis and provides more robust results remains important in growth empirics, hence this study. Thus, this study utilizes the nonparametric methodology to estimate the determinants of economic growth in sub-Saharan Africa over the period 1970 to 2012. The contribution of this study to the extant literature relies on the use of the local linear kernel estimator, a powerful nonparametric estimator which exists nowhere in growth literature related to sub-Saharan Africa.

Eventually, the findings of the study suggest that there is a positive and nonlinear relationship between real GDP on one hand as well as investment in physical capital, population and democracy on the other hand. This implies that in the long run, increases in gross capital formation (proxy for investment in physical capital), population and democracy would promote economic growth in sub-Saharan Africa, all things being equal. We also find that human capital and inflation have no significant effect on economic growth in SSA at least over the period considered for the study. Finally, we find in the study that foreign aid has negative effect on economic growth in SSA over the study period.

The findings highlighted above have important implications for growth policy in SSA in particular and growth empirics generally. An important finding of this study is the significant role population (a proxy for 
labour force and country size) plays in the growth process of SSA countries. However, as already discussed, population beyond certain threshold becomes detrimental to growth. Therefore, population control programmes should be intensified especially in the rural settings. Another interesting finding was the relationship between human capital (measured by gross primary school enrolment) and real GDP. The implication is that basic/primary education cannot provide the needed skills and training for manpower development to promote economic growth. Government policy should thus focus on expanding and improving the quality of education and enrolment especially at the higher levels through increased public spending on education. Furthermore, policies should also target strengthening democratic institutions to be more efficient and deepen the level of democracy to provide a more favourable political environment for investors and economic activities in general. Finally, in the area of research, the results obtained in this study imply that researchers should at all times be cautious in specifying the functional form of growth models when investigating the determinants of economic growth.

\section{References}

Acemoglu, D. (2009). Introduction to Modern Economic Growth, Princeton, NJ: Princeton University Press.

Acemoglu, D., Johnson, S., and Robinson, J. (2002). Reversal of fortune: geography and institutions in the making of the modern world income distribution, Quarterly Journal of Economics, 117 (4), 1231-94.

Adu, G. (2013). Determinants of Economic Growth in Ghana: Parametric and nonparametric investigations, Journal of Developing Areas, 47 (2), 277-301.

Aghion, P., and Howitt, P. (2009). The Economics of Growth, Cambridge, MA: MIT Press

Baltagi, B.H. (2001). Econometric Analysis of Panel Data, $2^{\text {nd }}$ Edition, New York: Wiley \& Sons.

Barro, R. J. (1998). Determinants of Economic Growth: A Cross-Country Empirical Study, Cambridge, MA: MIT Press.

Barro, R. J., and Sala-i-Martin, X. (2004). Economic Growth, $2^{\text {nd }}$ Edition, Cambridge, MA: MIT Press.

Benhabib, J., and Spiegel, M. (1994). The Role of Human Capital in Economic Development: Evidence from Aggregate Cross-Country Data, Journal of Monetary Economics, 34 (2), 143-173.

Boko, S.H. (2002). Economic reform, democracy, and economic growth in Africa: An institutional approach. International Advances in Economic Research, 8 (3), 264-281.

Cohen, D. and Soto, M. (2007). Growth and Human capital: Good Data, Good Results, Journal of Economic Growth, 12(1), 51-76.

Dollar, D., and Kraay A. (2000). Trade, Growth and Poverty, Working Paper, 2615, The World Bank Development Research Group, Washington D.C.

Dutta, M. (2005). China's industrial revolution: challenges for a macroeconomic agenda. Journal of Asian Economics, 15 (6), 1169-1202.

Easterly, W., and Rebelo, S. (1993). Fiscal Policy and Economic Growth, Journal of Monetary Economics, 32 (3), 417-458

Edwards, S. (1998). Openness, Productivity and Growth: What Do We Really Know? Economic Journal, 108 (447), 383-398.

Fagerberg, J. (1994), Technology and international differences in growth rates, Journal of Economic Literature, $32(3), 1147-1175$

Fagerberg, J., and Verspagen, B. (2002). Technology-Gaps, Innovation-Diffusion and Transformation: an Evolutionary Interpretation, Research Policy, 31, 1291-1304.

Fagerberg, J., and Verspagen, B. (2007). Innovation, Growth and Economic Development: Have the Conditions for Catch Up Changed? International Journal of Technological Learning, Innovation and Development, 1 (1), 1985-2008.

Fisher, S. (1993), The Role of Macroeconomic Factors in Growth, Journal of Monetary Economics, 32 (3), 485 512 .

Fosu, A. K. (1990). Exports and Economic Growth: The African Case, World Development, 18 (6), 831-835.

Fosu, A. K., and Ndungu, N. (1999). Explaining Slow Growth in Africa, paper presented at the Second Workshop - Can Africa Claim the 21st Century? Abidjan, Cote d' Ivoire.

Frankel, J. A., and Romer, D. (1999). Does trade cause growth? American Economic Review, 89 (3), $379-399$.

Glaeser, E.L., La Porta, R., Lopez-de-Silanes, F., \& Shleifer, A. (2004). Do institutions cause growth? Journal of Economic Growth, 9 (3), 271-303.

Grier, K., and Tullock, G. (1989). An empirical analysis of cross-national economic growth, 1951-1980, Journal of Monetary Economics, 24 (2), 259-276.

Gyimah-Brempong, Racine, J.S. and Gyapong, A. (2010). Aid and Economic Growth: Sensitivity Analysis, Journal of International Development, 10 (1), 7-17.

Hall, R., and Jones, C. (1998). Why do Some Countries Produce so Much More Output than Others? The Quarterly Journal of Economics, 114, 83-116. 
Hanushek, E. and Kimko, D. (2000). Shooling, Labor-Force Quality, and the Growth of Nations, American Economic Review, 90, 1184-1200.

Harrison, A. (1991). Openness and Growth: A Time Series Cross-Country Analysis for Developing Countries, Policy Research Papers, No. 809, World Bank, Washington, DC.

Hsiao, C., Li, Q. and Racine, J. S. (2007). A consistent model specification test with mixed categorical and continuous data, Journal of Econometrics, 140, 802-26.

Hurvich, C. M., Simonoff, J. S., and Tsai, C. L. (1998). Smoothing parameter selection in nonparametric regression using an improved Akaike information criterion, Journal of the Royal Statistical Society Series, B $66,463-477$.

Krueger, A., and Lindhal, M. (2001). Education for Growth: Why and For Whom? Journal of Economic Literature, 39 (4), 1101-1136.

Li, Q., and Racine, J.S. (2007). Nonparametric Econometrics: Theory and Practice, Princeton, NJ: Princeton University Press.

Li, Q., and Racine, J.S. (2004). Cross-Validated Local Linear Nonparametric Regression, Statistica Sinica, 14, 485-512.

Lucas, R. (1988). On the Mechanisms of Economic Development, Journal of Monetary Economics, 22, 3-42.

Mankiw, N., Romer, D., and Weil, D. (1992). A Contribution to the Empirics of Economic Growth, Quarterly Journal of Economics 107(2), 407-437.

Minier, J.A. (1998). Democracy and growth: Alternative approaches. Journal of Economic Growth, 3 (3), 241266.

Morrissey, O., Gomanee, K., and Girma, S. (2005). Aid and growth in Sub-Saharan Africa: Accounting for transmission mechanisms, Journal of International Development, 17(8), 1055-1075.

Myint, H. (1980). The Economics of the Developing Countries, $5^{\text {th }}$ Edition, London: Hutchinson Press.

Rodriguez, F., and Rodrik, D. (1999). Trade Policy and Economic Growth: a Skeptic's Guide to the Crossnational Evidence, NBER Working Paper, 7081, Cambridge, MA.

Romer, D. (2006). Advanced Macroeconomics, $3^{\text {rd }}$ Edition, New York: McGraw-Hill.

Romer, P. (1994). New Goods, Old Theory and the Welfare Costs of Trade Restrictions, Journal of Development Economics, 43, 5-38

Romer, P. (1990). Endogenous Technological Change, Journal of Political Economy, Vol. 98 (5), 71-102.

Sachs, J., and Warner, A.M. (1997). Sources of Slow Growth in African Economies, Journal of African Economies, 6 (3), 335-376.

World Bank (2013). World Development Indicators, Washington, DC: World Bank.

World Bank (2013). African Development Indicators, Washington, DC: World Bank.

Yanikkaya, H. (2003). Trade Openness and Economic Growth: A cross country empirical investigation, Journal of Development Economics, 72 (5), 57-89. 